\title{
Maternal and fetal outcome in cases of eclampsia
}

\author{
Hetal N. Dodiya*, Sapana R. Shah, Rupa C. Vyas, Purvi M. Parikh
}

Department of Obstetrics and Gynaecology, Smt. NHL Medical College and SVPIMSR, Ahmedabad, Gujarat, India

Received: 23 July 2020

Accepted: 06 October 2020

\section{*Correspondence:}

Dr. Hetal N. Dodiya,

E-mail: drhnd2810@gmail.com

Copyright: (C) the author(s), publisher and licensee Medip Academy. This is an open-access article distributed under the terms of the Creative Commons Attribution Non-Commercial License, which permits unrestricted non-commercial use, distribution, and reproduction in any medium, provided the original work is properly cited.

\begin{abstract}
Background: Eclampsia refers to occurrence of generalized tonic clonic convulsions (GTCS) followed by confusion or coma during pregnancy or puerperium in patients with preeclampsia excluding other neurological conditions. Purpose of this study was to evaluate the risk factors, management protocols and determine maternal and perinatal morbidity and mortality in patients of eclampsia.

Methods: This is retrospective study of 180 cases of eclampsia carried out from June 2017 to December 2019 including all the antepartum, intrapartum and postpartum cases at tertiary care centre. Immediate management was focused to control the convulsion and lower the blood pressure followed by NST and USG foetus with Doppler study. Results: In this study, $72.2 \%$ cases reported antepartum eclampsia while $27.8 \%$ cases were postpartum and overall incidence was $0.91 \%$ of total deliveries conducted during the study period. Incidence was higher in primigravida $(74.4 \%)$ and below 25 years age (68.8\%). Magnesium sulphate was effective in $94.4 \%$ cases. Study reports 63 normal vaginal delivery, 5 assisted vaginal delivery, 110 caesarean section and 2 women expired undelivered. There were 10 maternal deaths.

Conclusions: Time interval between eclamptic seizures and initiation of therapy is an important prognostic factor affecting maternal and perinatal outcome. Public awareness regarding the importance of regular antenatal visits can help in reducing chances of development of eclampsia. Even though various drugs and methods have been tried for the treatment of eclampsia, the definitive management is the delivery of foetus after control of convulsion, hypertension and should be managed at tertiary care hospital.
\end{abstract}

Keywords: Pre-eclampsia, Eclampsia, Perinatal outcome, Maternal mortality

\section{INTRODUCTION}

Eclampsia is the development of seizures that cannot be attributed to other causes and/or unexplained coma during pregnancy or puerperium in a woman with preeclampsia. ${ }^{1}$ Eclampsia refers to occurrence of GTCS followed by confusion or coma during pregnancy or puerperium in patients with preeclampsia and excluding other neurological conditions. ${ }^{1,2}$

Eclampsia is a serious complication of preeclampsia. Preeclampsia is characterized by hypertension $(\geq 140 / 90$ $\mathrm{mmHg}$ ) and proteinuria (>300 mg/24 hours) after 20 weeks of gestation. ${ }^{3}$ The main pathology might be generalized vasoconstriction and the endothelial dysfunction. Preeclampsia is more likely to develop in women who are exposed to chorionic villi first time, having pre-existing vascular disease, genetically predisposed to hypertension during pregnancy and superabundance of exposure of chorionic villi as in multiple pregnancy, vesicular mole etc. ${ }^{1,4,7}$

Soluble fms-like tyrosine like kinase 1 (sFlt1) is a variant of receptor for placental growth factor (PLGF) and vascular endothelial growth factor receptor (VEGF). Increased maternal level of sFlt1 inactivate and decrease circulating VEGF and PLGF concentration leading to endothelial dysfunction. ${ }^{5}$ 
Seizures are due to the development of abnormal foci of electrical discharges that generalizes causing convulsion which are result of an abnormal auto regulatory response consisting of severe arterial vasospasm. Possible mechanisms of convulsion can be due to cerebral vasospasm, infarction, hemorrhage, oedema and hypertensive and metabolic encephalopathy. ${ }^{1,6}$ Eclampsia has remained as one of the major causes of maternal and perinatal morbidity as well as mortality. Ante partum eclampsia is more common and is more dangerous than postpartum eclampsia. ${ }^{7}$ Prevention of eclampsia is the key to reduce complication and hence to decrease the morbidity and mortality in patients of preeclampsia. By individualizing the dose of aspirin and calcium supplementation, the risk of preeclampsia can be reduced in some patients., ${ }^{1,5}$ The complications of severe preeclampsia and eclampsia can lead to multi organ dysfunction and hence death due to eclampsia is high.

The objective of this study was to evaluate the risk factors, management protocols and determine the maternal and perinatal morbidity and mortality in diagnosed cases of eclampsia.

\section{METHODS}

This is a retrospective study of 180 cases of eclampsia from June 2017 to December 2019 carried out at tertiary care centre. This study is conducted to analyses the cases in reference to age, parity, antenatal care, gestational age, fetomaternal outcome in eclampsia. Data was collected in a preconceived format from the case files of patients with eclampsia which were traced through labour ward registers.

All laboratory investigations and radiological assessments included complete blood cell count (CBC), liver function test (LFT), renal function test (RFT), coagulation profile, serum uric acid (UA), serum lactate dehydrogenase (LDH), urine for protein, NST, USG foetus including fetal doppler study, USG abdomen and chest were performed. All the patients were managed by multidisciplinary approach that includes obstetrician, anesthetist, physician and neonatologist.
Immediate management done by shifting patient in semi dark noiseless room on railed cot, mouth gag inserted, suctioning done, iv line secured. Four grams of Mgso4 as $20 \%$ solution IV at a rate not exceeding $1 \mathrm{gm} / \mathrm{min}$. followed by $10 \mathrm{gm}$ of $50 \% \mathrm{MgSO}_{4}$, one half $(5 \mathrm{gm}$ ) injected deeply I.M. in each buttock (Pritchard's regimen). When convulsions persist after 15 mins, $\mathrm{MgSO}_{4}$ was given up to $2 \mathrm{gm}$ more intravenously as a $20 \%$ solution at a rate not exceeding $1 \mathrm{gm} / \mathrm{min}$. Antihypertensive drug given. Injection labetalol $20 \mathrm{mg}$ IV bolus if not effective within 10 minutes, this was followed by $40 \mathrm{mg}$, then $80 \mathrm{mg}$ every 10 minutes but not to exceed a $220 \mathrm{mg}$ total dose per episode treated. Subsequently maintenance dose of $\mathrm{MgSO}_{4}$ continued for 24 hours (5 gm IM 6 hourly/4 gm IM 4 hourly) after delivery or last convulsion whichever is later. These patients were closely monitored for urine output, knee jerk (deep tendon reflexes) and respiratory rate. After control of convulsion and hypertension, delivery planned.

Inclusion criteria included all ante partum, intra partum and postpartum cases of eclampsia during this period were included in this study.

Exclusion criteria excluded patients diagnosed as convulsion due to cerebral causes, epilepsy or any other organic causes were excluded from this study.

\section{RESULTS}

The antepartum eclampsia (APE) cases were 130 (72.2\%) and the postpartum eclampsia (PPE) cases were 50 $(27.8 \%)$. The incidence of eclampsia was $0.91 \%$ (180/19568) of all deliveries conducted at our centre. Most number of eclampsia cases was in the 21-25 years age group with $55.5 \%$ incidence while in women older than 35 years only 2 cases reported with an incidence of $1.1 \%$ The study indicated that it's a disease of primigravida with 134 cases out of 180 with $74.4 \%$ incidence. In multigravida 46 cases reported with an incidence of $25.6 \%$

Table 1: Demographic parameters.

\begin{tabular}{|llll|}
\hline Age group (years) & Number of cases $(\boldsymbol{\%})$ & Parity & Number of cases $(\%)$ \\
\hline $\mathbf{2 0}$ & $24(13.33)$ & 0 & $134(74.4)$ \\
\hline $\mathbf{2 1 - 2 5}$ & $100(55.5)$ & 1 & $26(14.1)$ \\
\hline $\mathbf{2 6 - 3 0}$ & $30(16.6)$ & 2 & $10(5.5)$ \\
\hline $\mathbf{3 1 - 3 5}$ & $24(14.3)$ & 3 & $9(5)$ \\
\hline $\mathbf{3 5}$ & $2(1.1)$ & $\geq 4$ & $1(0.5)$ \\
\hline
\end{tabular}

In this study, pre-existing risk factors associated with eclampsia included obesity (BMI>30) in 47.2\% (85/180), anemia $26.6 \%$ (48/180), history of gestational hypertension in $16.6 \%(30 / 180)$, history of chronic hypertension in $11.1 \%(20 / 180)$, and history of eclampsia in previous pregnancy in $1.6 \%$ (3/180) cases. The incidence of various impending signs and symptoms of eclampsia are depicted in the figure 1. 


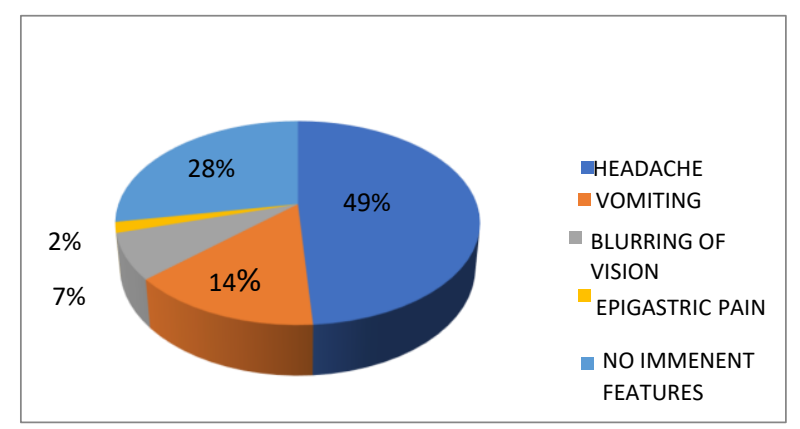

Figure 1: Impending symptoms of eclampsia.

In this study, $117 / 180(65 \%)$ cases presented with severe hypertension $(\mathrm{BP} \geq 160 / 110 \mathrm{mmHg})$ and proteinuria was present in $94.4 \%(170 / 180)$ cases. Elevated serum levels of $\mathrm{LDH}$ (>600 IU/L) were observed in $73.8 \%$ (133/180), increased serum uric acid in $52.7 \%$ (95/180), platelet count was below 1,50,000 in 44.4\% (80/180).

In present study $94.4 \%(170 / 180)$ cases of eclampsia responded well to $\mathrm{MgSO}_{4}$ therapy (Pritchard's regimen). This study reports that $\mathrm{MgSO}_{4}$ therapy is drug of choice in cases of eclampsia and very effective in controlling convulsions. Despite of administering $\mathrm{MgSO}_{4}$, recurrent seizures were observed in some women and they needed additional anticonvulsant therapy. In this study $5.6 \%$ $(10 / 180)$ women of eclampsia were given additional anticonvulsant therapy in form of injection levetiracetam.

In this study $37.8 \%(68 / 180)$ had vaginal delivery including 5 cases of instrumental delivery and $61.1 \%$ $(110 / 180)$ of patients had caesarean section.
Table 2: Mode of delivery.

\begin{tabular}{|ll|}
\hline Pregnancy outcome & Percentage (\%) \\
\hline Vaginal delivery & $63(35)$ \\
\hline Assisted vaginal delivery & $5(2.8)$ \\
\hline Caesarean section & $110(61.1)$ \\
\hline Expired undelivered & $2(1.1)$ \\
\hline
\end{tabular}

In this study, there were 150 live births while 18 were stillbirth. Among 150 live births, 42 babies were admitted in NICU from which 12 babies expired due to prematurity (7/12), thick meconium aspiration (2/12), septicemia (2/12) and birth asphyxia (1/12). Because of presence of neonatologist at time of delivery with wellequipped neonatal setup, incidence of perinatal mortality in our institution is less as compared to other studies.

Table 3: Perinatal outcome.

\begin{tabular}{|ll|}
\hline Perinatal outcome & Percentage $(\%)$ \\
\hline Total live birth & $150(83.3)$ \\
\hline NICU admission & $42(23.3)$ \\
\hline Still birth & $18(10)$ \\
\hline Early neonatal death & $9(5)$ \\
\hline Late neonatal death & $3(1.7)$ \\
\hline
\end{tabular}

Most common complication in our study was abruption of placenta due to placental separation with $8.9 \%$ while postpartum hemorrhage (PPH) was found in $7.8 \%$ cases. Prematurity $(28.9 \%)$ was the most common complication followed by FGR in $20 \%$ foetus.

Table 4: Maternal and foetal complications.

\begin{tabular}{|l|l|}
\hline Obstetrics complications & Percentage $(\%)$ \\
\hline Abruption of placenta & $16(8.9)$ \\
\hline PPH & $14(7.8)$ \\
\hline DIC & $12(6.7)$ \\
\hline HELLP syndrome & $10(5.6)$ \\
\hline Puerperal sepsis & $5(2.8)$ \\
\hline Postpartum psychosis & $4(2.2)$ \\
\hline Cerebral complications & $6(3.3)$ \\
\hline Status epilepticus & $9(5)$ \\
\hline PRES & $4(2.2)$ \\
\hline Transient blindness & $3(1.7)$ \\
\hline ICH & \\
\hline Vascular complication & $7(3.9)$ \\
\hline Renal failure & $5(2.8)$ \\
\hline Aspiration pneumonitis and ARDS & $7(3.9)$ \\
\hline Pulmonary oedema & \\
\hline Fetal complication & $52(28.9)$ \\
\hline Prematurity & $36(20)$ \\
\hline FGR foetus & $16(8.9)$ \\
\hline Respiratory distress syndrome & $15(8.3)$ \\
\hline Intrauterine death & $8(4.4)$ \\
\hline Meconium aspiration syndrome & $1(0.5)$ \\
\hline Intraventricular hemorrhage & \\
\hline
\end{tabular}


In present study of 180 cases maternal mortality rate was $5.6 \%$ (10/180). Most common cause of maternal mortality in this study was DIC followed by HELLP syndrome.

Table 5: Maternal mortality.

\begin{tabular}{|ll|}
\hline $\begin{array}{l}\text { Causes of maternal } \\
\text { mortality }\end{array}$ & $\begin{array}{c}\text { Percentage }(\%) \\
\text { (Total mortality=10) }\end{array}$ \\
\hline DIC & $6(3.3)$ \\
\hline HELLP Syndrome & $2(1.1)$ \\
\hline ARDS & $1(0.56)$ \\
\hline ICH & $1(0.56)$ \\
\hline
\end{tabular}

\section{DISCUSSION}

This disease is more prevalent in young and nulliparous women. In this study 180 patients of eclampsia were analysed with regards to their clinical signs and symptoms, correlation with age, parity, mode of delivery, management, their fetomaternal outcome and various complications which occurred in patients of eclampsia. The incidence of eclampsia in this study reported was $68.8 \%(124 / 180)$ in women below the age of 25 years which is comparable with the studies conducted by Bembalgi et al (59.2\%). ${ }^{8}$ Present study showed $74.4 \%$ $(134 / 180)$ of cases were primigravida while $25.6 \%$ $(36 / 180)$ of cases were multi gravida which is comparable to studies by Sunita et al in which it is 79 and $21 \%$ respectively. ${ }^{9}$ It suggests primigravida patients are predisposed to the risk of preeclampsia as they are exposed to chorionic villi for the first time. In majority of cases onset of eclampsia was preceded by persistent headache $(48 \%)$ which was throbbing in nature, in occipital or frontal region, and in other cases, vomiting (14\%), visual symptoms (7\%) and epigastric pain (2\%) and this is greater in incidence than study by Gupte et al in which it is 22,10,4 and 3\% respectively. ${ }^{10}$ Incidence of eclampsia is higher in ante partum patients $72.2 \%$ (130) is comparable to study by Gupte et al $(76.7 \%) .{ }^{10}$

Early detection and proper antenatal management of preeclampsia reduces the incidence of eclampsia. All the patients were divided into mild and severe variety according to Williams' criteria. In present series of cases nearly $65 \%$ cases presented with severe hypertension with blood pressure $\geq 160 / 110 \mathrm{mmHg}$. Uric acid was raised in $52.7 \%$ cases and it is comparable to Zafar et al $(53.5 \%) .{ }^{11}$ In this study, $94.4 \%(170 / 180)$ cases of eclampsia responded well to Mgso4 therapy while 5.6\% $(10 / 180)$ cases required additional anticonvulsant therapy in the form injection levetiracetam which is comparable to Sunita et al in which it is $2 \% .^{9} \mathrm{MgSO}_{4}$ reduces presynaptic release of glutamate, improves mitochondrial calcium buffering and blockage of calcium entry. ${ }^{12,13}$

Severe preeclampsia can give rise to stroke and hemorrhagic complications, increase chances of development of eclampsia and associated with high maternal morbidity and mortality. The decision to perform caesarean section should be based on bishop score, progress of labour, foetal gestational age and wellbeing, and maternal condition. In our study $37.8 \%$ $(68 / 180)$ had vaginal delivery including 5 cases of instrumental delivery and $61.1 \%$ (110/180) of patients had caesarean section which is comparable with studies by Tukur et al in which $42.3 \%$ had vaginal delivery and $51.7 \%$ had caesarean section. ${ }^{14}$ Timely selection of cases for either vaginal delivery or caesarean section is going to improve the maternal and perinatal outcome. In recent years, caesarean section has been opted for the mode of delivery especially in salvageable babies and cases of failed induction. This has resulted in a better perinatal outcome. There were 150 (83.3) live birth which is comparable with Sunita et al (94\%). ${ }^{9}$ This study reports $18(10 \%)$ still birth and $12(6.7 \%)$ neonatal death which is lower in incidence compared to Tukur et al which reports $22.5 \%$ of still birth and $9.1 \%$ neonatal death. ${ }^{14}$ The reduced incidence of neonatal mortality can be attributed to timely intervention, presence of neonatologist at the time of delivery and well equipped NICU.

With increasing severity of disease many fetomaternal complications occur like abruptio placenta, hepatorenal dysfunction, intracerebral hemorrhage, pulmonary oedema, cardiopulmonary arrest, status eclampticus, cortical blindness, intrauterine death, foetal growth restriction, preterm birth, neonatal asphyxia. Most common complication reported was HELLP syndrome (4.2\%) followed by abruption (2.5\%) in study by Tukur et al. ${ }^{14}$ But present study reported abruption in $8.9 \%$ and HELLP in $5.6 \%$ of the cases. Pulmonary oedema developed in $3.8 \%$ of the cases that is comparable to Tukur et al study that reported 5\%. ${ }^{14}$ These patients were admitted to ICU, monitored constantly under guidance of critical care specialist. Among foetal complications, prematurity $(28.9 \%)$ was most common followed by FGR (20\%) that is lower than study conducted by Bhalerao et al (41.8\% Prematurity and $27.27 \%$ FGR). ${ }^{15}$

The present study reported maternal mortality in 10 cases (5.6\%). Among them 6 (3.3\%) women expired due to DIC, 2 women $(1.1 \%)$ due to HELLP syndrome, $1(0.56 \%)$ due to $\mathrm{ICH}$, and $1(0.58 \%)$ due to acute respiratory syndrome (ARDS). Poor antenatal care and delayed hospitalization was noted in all women who died.

\section{CONCLUSION}

Preeclampsia is a very common pregnancy associated disorder involving multi organs. Once eclampsia occurs, it carries a high maternal and perinatal mortality. The key to prevent is proper antenatal check-ups with availability of health facilities to every level of health care. High incidence of eclampsia is seen in primigravida patients. Public awareness regarding the importance of regular antenatal check-up can help in reducing chances of occurrence. Time interval between eclamptic seizures and initiation of therapy is an important prognostic factor 
affecting maternal and perinatal outcome. Magnesium sulphate as a drug of choice has stood the test of time for the control of eclampsia and prevention of further convulsions. Even though various drugs and methods have been tried, the definitive management for the treatment of eclampsia is after controlling of seizures and hypertension, delivery at tertiary care hospital. The mode of termination should be individualized. Early diagnosis of preeclampsia, its proper management and timely delivery will improve maternal and perinatal outcome and decreases the rate of complications.

Funding: No funding sources

Conflict of interest: None declared

Ethical approval: The study was approved by the Institutional Ethics Committee

\section{REFERENCES}

1. Cunningham FG. Obstetrical haemorrhage. In: Cunningham, Leveno Bloo, Spong, Dashe, Hoffman, Casey, Sheffield. Williams Obstetrics $25^{\text {th }}$ ed. New York, NY: McGraw-Hill. 2019:755-95.

2. National high blood pressure education program working group report on high blood pressure in pregnancy. Am J Obstet Gynecol. 1990;163:1689712 .

3. Mushambi MC, Halligan AW, Williamson K. Recent developments in the pathophysiology and management of pre-eclampsia. $\mathrm{Br} \mathrm{J}$ Anaesth. 1996;76:133_48.

4. Ian Donald's Practical Obstetrics problems; $7^{\text {th }}$ edi, chapter 8: Hypertensive disorders. 2014;142-75.

5. Sibai BM. Hypertension. In Gabbe SG, Niebyl JR, Simpson JL, Landon MB, Galan HL, Jauniaux HRM, Driscoll DA (Eds.), Obstetrics: Normal and problem pregnancies $6^{\text {th }}$ ed Philadelphia, PA: W. B. Saunders. 2012;631-66.

6. ACOG Committee on Obstetric Practice. ACOG practice bulletin. Diagnosis and management of preeclampsia and eclampsia. Number 33, January 2002. Obstet Gynecol. 2002;99(1):159-67.

7. Arulkumaran N, Lightstone L. Severe pre-eclampsia and hypertensive crises. Best Practice Res Cli Obste Gynaecol. 2013;27(6):877-84.

8. Bembalgi S, Kamate V, Shetty S. A Comparative study of antepartum and postpartum eclampsia at a tertiary care centre. 2016;5(6);1728.

9. Sunita TH, Desai RM. Eclampsia in a teaching hospital; incidence, clinical profile and response to magnesium sulphate by zuspan's regimen. J dental med sci. 2013;4(2):1-5.

10. Gupte S, Wagh G. Preeclampsia- Eclampsia. j obstet gynecol India. 2014;64(1):4-13.

11. Mary VP, Cnellatamizh M, Padmanaban S. Role of serum LDH in preeclampsia as a prognostic factor- a cross sectional case control study in tertiary care hospital. Int J Reprod Contracept Obstet Gynecol. 2017;6(2);595-8.

12. Pritchard JA. The use of magnesium ion in the management of eclamptogenic toxemia. Surg Gynecol obstet. 1995;100:131-40.

13. Duley L, gulmezogly AM, magnesium sulphate versus lytic cocktail for eclampsia. Cochrane database syst. Rev. 2001;(1):CD 002960.

14. Tukur J, Umar BA, Rabi'u A. Pattern eclampsia in a tertiary health facility situated in a semi-rural town in Northern Nigeria. Ann Afr Med. 2007;6(4):164.

15. Bhalerao A, Kulkarni S, Ghike S, Kawthalkar A, Joshi S, Somalwar S. Eclampsia: Maternal and Fetal Outcome. J South Asian federation obstet Gynecol. 2013;5(1):19-21.

Cite this article as: Dodiya HN, Shah SR, Vyas RC, Parikh PM. Maternal and fetal outcome in cases of eclampsia. Int J Reprod Contracept Obstet Gynecol 2020;9:4432-6. 